\title{
Comparing environmental values across major U.S. national parks
}

\author{
D. B. Rideout, P. S. Ziesler \& Y. Wei \\ Fire Economics and Management Laboratory, \\ Department of Forest, Rangeland and Watershed Stewardship, \\ Colorado State University, USA
}

\begin{abstract}
Environmental values at four of America's most famous national parks are assessed through a structured survey technique. Resource and wildland fire managers in Sequoia and Kings Canyon, Yellowstone, Grand Canyon, and Rocky Mountain national parks were surveyed to identify the most important values that could be improved or that should be protected from wildland fire. In some instances wildland fire can produce beneficial effects on the landscape by treating vegetation to restore or maintain the natural system. In other circumstances, wildland fire can severely affect life, property and treasured natural resources. This research identifies the key sets of values potentially affected by wildland fire across each of the four national parks and compares the relative importance of each kind of value. With a diverse set of famous North American national parks, this research shows which values they share and which values are unique. This was accomplished by implementing a structured and peer-reviewed elicitation process. For the first time, we show the set of values important to each of these national parks and how they compare and contrast.

Keywords: Grand Canyon, Yellowstone, Rocky Mountain, Sequoia Kings Canyon, valuation, nature's services, environmental capital, meta-value, disturbance, wildland fire.
\end{abstract}

\section{Introduction}

America's national parks contain some of the most treasured natural resources in the country and the world. While each national park is unique in its natural features and unique in its enabling purposes and legislation, all parks share a 
common sense of environmental purpose and value. For example, some parks contain unique forest cover types, such as the famous sequoia trees in southern California, while others are home to critical wildlife habitats, such as the northern Goshawk. However, given the mission of national park management, we would also expect the parks to exhibit some similarities in valuation. Exploration of valuation across America's national parks has not previously been approached using a quantitative framework. Fundamental questions of interest for understanding the importance of nature's (natural) services and the importance of environmental capital include:

- Can unique national parks be characterized by a shared set of metavalue attributes (shared environmental values)?

- If they can be characterized by common meta-value attributes, how do the individual attribute values compare across the diverse parks?

The first question seeks to identify if there are common categories of value shared among the parks. For example, while there are unique cover types and unique wildlife species, can workable general categories be constructed that can then be used to address valuation across parks? The second question is contingent upon a positive response to the first. For example, if meta-value categories can be formed that apply across the parks, we would want to know if and where the values show consistency and where they show differences. These questions are of general interest in environmental and resource management and they can provide valuable insight and information for resource planning and environmental compliance. This paper will address the characterization and comparison of values for national parks in the context of disturbance management - particularly the management of wildland fire. Value information for disturbance management is broadly useful because it can be employed for planning exercises and compliance and it may be used in a general context for evaluating resource value changes from disturbances.

Like all natural systems, national parks are subject to natural disturbances such as hurricanes, insect infestations and wildfire. A consequence of disturbances is that they often inflict a wide array of resource changes [1] and a corresponding array of changes in resource values. In wildland fire management, disturbances usually affect multiple resources where some resources are improved and others may be damaged. For example, a single low-intensity wildland fire might have a positive impact on cultural resources such as Giant Sequoia groves and a negative impact on habitat for sensitive wildlife. Capturing the directions and relative magnitudes of such value changes is critical for evaluating potential management responses to a fire disturbance.

Valuation for disturbance management typically uses marginal values rather than total values because both management activities and disturbances usually produce marginal changes (modest increases or decreases) to the level of natural services and/or environmental capital stock. Our valuation comparisons rely on the ideas that 1) resource value changes are marginal or incremental and 2) that the marginal values are measured on the same numeric cardinal scale (they are relative values). The data set used to estimate fire value comparisons among the 
four national parks includes a list of resource values affected by wildland fire and the relative change in value (marginal value) induced by wildland fire under specified conditions.

In 2008, the U.S. federal government spent approximately $\$ 3.0$ billion on wildland fire suppression and related activities and another $\$ 3.25$ billion [2] on fuel treatment. In some federal agencies, including the U.S. Forest Service, expenditures on managing fire disturbance now comprise a majority of the agency budget. Information on resource value changes related to disturbance events, including wildland fire has, perhaps, never been so timely. Because forest disturbances affect the flow of nature's services and the value of the underlying environmental asset, a clear and pragmatic understanding of the value changes involved can promote viable levels of natural services and corresponding asset values. Understanding such value changes can assist resource managers by aiding in selection of the most appropriate intervention(s) and by guiding the placement of mitigation actions, such as fuel treatments, on the landscape. Such information is highly useful for assessing land management planning and in addressing specific loss mitigation strategies.

The paper is organized as follows: after a brief review of previous work in resource and disturbance valuation we discuss the elicitation of resource value attributes and their values for each national park. We used the MARS elicitation method [3] on each park to establish the pertinent list of resource values affected by fire and the marginal values for each resource under various ecosystem conditions and fire intensities. The results and discussion and conclusions sections provide the comparisons and contrasts of the resulting valuation data.

\section{Previous work}

Since the publication of Paul Samuelson's work on pubic goods [4, 5], resource economists have laboured to develop the theory and techniques of resource valuation. Today's formal techniques for assessing environmental values are intensive, costly and primarily resource specific. Most of the accepted techniques reflect enormous advances since Samuelson's work, but they are not readily applied to the wide array of resources affected by wildland fire. Consequently, resource managers and planners are saddled with the problem of generating resource disturbance values for strategic, long-term program planning, and for rapid response planning when a disturbance strikes. Fire managers are routinely required to make resource management decisions involving the marginal valuation of a wide range of natural resources. They are required to make mitigation or enhancement decisions quickly when there is an increment of value to add or to protect by managing a fire event. Most fires, including prescribed burns, will promote modest changes to the fuel conditions on a landscape. Such an incremental change is often appropriately addressed through "marginal analysis".

Since the work of Samuelson, resource economists have focused on applying principles of demand theory to address the valuation problem and they have been careful to distinguish between total value (the value of a defined quantity 
enjoyed), marginal value (the change in total value resulting from small changes in quantity) and consumer surplus (the total consumer benefit minus payment). While most studies and applications of valuation theory address total value and consumer surplus and thereby enable an estimate of marginal value [6], few directly estimate marginal values; especially across the set of resources impacted by disturbance.

A recent survey of modern valuation techniques [7] explained the use of an array of "revealed preference" and "stated preference" techniques. In addition, the field of "experimental economics" is expanding upon the application of stated preference theory through structured experimental design [8]. Revealed preference techniques rely on observing choices that resource users (or consumers) make. Revealed preference techniques include the classic travel cost method, where expenditures on travel are observed and analyzed to estimate outdoor recreation values. While revealed preference techniques have the advantage of using observed behaviour, they are impossible to use where valuation of natural systems involves non-use values. Non-use values include concepts such as a society's value for the ability to transfer natural treasures to future generations or an individual's value of knowing that a resource exists. Stated preference methods do not rely on observed choices but have the important advantage of being able to address non-use public good values such as the value of preserving resources for future generations, while not sacrificing the ability to address use values. Stated preference techniques have greatly advanced in recent years and include a variety of contingent valuation methods and a family of hedonic approaches [7]. Despite such great strides in theory and techniques, land managers continue to face an important scarcity of information on marginal values. Much of the valuation information that is available pertains only to a specific resource condition. This specificity prevents it from being reliably applicable to other resources or conditions. Further, some estimates are too general to be credible at the planning unit level. Techniques are needed that directly apply to the wide range of resources potentially affected by disturbances and that are appropriate for the local planning unit level.

To address the issue of pragmatic relevance of resource values for fire management planning, Rideout et al. [3] developed an approach to estimate marginal relative values at the planning unit level. The approach, known as "Marginal Attribute Rates of Substitution" (MARS), requires a structured elicitation of values from fire and resource management officials at the local planning unit level. MARS was successfully applied at the Sequoia and Kings Canyon National Parks (SEKI) in May 2005. The MARS process required about two days of intense elicitation and the information supplied through MARS was used to inform fire management and firefighting efforts on the SEKI landscape during the 2008 fire management season.

After SEKI, MARS was applied at Grand Canyon (GRCA), Yellowstone (YELL) and Rocky Mountain (ROMO) parks yielding a four-park data set of marginal valuation information that has not previously been analyzed. The four parks include famous national treasures and each has important fire and resource management issues requiring information on marginal valuation. The addition of 
these three parks provides an interesting set of valuation data that addresses important differences among the ecosystems and the extent that values across the ecosystems are similar or different.

\section{Data sources and methods}

Rideout et al. [3] and others found that the valuation problem for disturbances such as wildland fire differs different from direct valuation of the resource. Because value changes associated with disturbances are rarely collected or documented in land and resource management planning processes, marginal valuation estimates for fire management were elicited from managers at each of the four national parks. While each national park is unique, there are important similarities among them with respect to fire management and valuation as shown below.

\subsection{The parks}

Sequoia and Kings Canyon National Park (SEKI), located in the Sierra range in southern California, contains the unique and famous sequoia groves including "named trees" of special importance such as the "General Sherman" tree and the Grant Grove. Sequoias are a fire-adapted species with thick bark to protect them from low-intensity fire events. The fire return interval for sequoias is relatively short at approximately 17 years. Frequent low-intensity fires in the groves provide benefits by clearing out encroaching vegetation and removing fuels that could ultimately produce a catastrophic event. The park is also home to other forest cover such as the "mixed conifer" type. Mixed conifer is known for its longer fire return interval, thin bark and abundant ladder fuels that enable fires to travel up trees into the crown where they can increase in intensity and rapidly spread. SEKI is also home to ponderosa pine. Although not unique like sequoia, ponderosa pine with its thick bark shares many fire behaviour and effect characteristics with the sequoia. Grand Canyon National Park located along the Colorado River in Arizona and Utah shares some similarities with SEKI. Both parks have high-value cultural resources that are affected by fire and management activities. There are also important differences between the parks in that GRCA does not have the same topographic profile as SEKI and it is home to tree types and wildlife not present in SEKI, such as the pinion-juniper (PJ) cover type and the goshawk.

In contrast, Rocky Mountain National Park (ROMO) and Yellowstone National Park (YELL) are located in the high elevation Rocky Mountains, are known for their long fire return interval cover types and contain different fireadapted species than SEKI or GRCA. ROMO is located in northern Colorado and contains the headwaters of the Colorado River that ultimately flow through GRCA. YELL is located in northwestern Wyoming and is famous for its geothermic sites and variety of wildlife. Similar to SEKI and GRCA, these parks contain mixed conifer type, but they also have vast stands of lodgepole pine. The lodgepole pine, while fire adapted, responds differently than the sequoia or 
the ponderosa. Fires in lodgepole pine are often referred to as "stand replacing" because entire stands are designed to be well consumed and then regenerated by wildfire. Individual trees reproduce by shooting seed from their cones when activated by heat. Such similarities and differences in vegetation types between the parks make for informative pairwise comparisons.

An interesting condition of the short fire return interval ecosystems is that while the desired condition can quickly degrade, it can also readily be returned to a more desirable state by using fire as a treatment. When these systems do not experience fire consistent with their natural return interval (they miss a return interval by chance or by an active fire suppression program), they begin to change in undesirable ways. With missed intervals they accumulate fuels and other understory and tree species may "invade". Here, stand and ecosystem conditions can benefit from reintroducing fire through fuel treatments or by allowing ignitions to play their natural role. In contrast, cover types with longer fire return intervals are typically considered to be in a "steady state" of ecosystem maintenance. While they can benefit from fire, the amount of time required for departure from the natural condition is lengthy. Hence, they will not register positive marginal values for fire in the same way as the short return interval parks.

\subsection{Value elicitation using the MARS method}

Application of MARS [3] to each park entailed assembling a full set of fire management planners to form an "expert" group. This group included resource management specialists, cultural resource specialists, fire management operations specialists and land management planners. Given the direction from their land management and fire management plans they identified the list of natural resources (known as value attributes) they actively manage for positive and negative fire effects. First, each expert group identified a set of value attributes appropriate to their park. Value attributes are a specific type of resource affected by fire such as high value development areas, sequoia groves (SEKI only) or lodgepole pine cover type (YELL, ROMO). Cover types are often a proxy for a set of resources associated with the cover. Next, as appropriate, value attributes are further categorized by ecosystem condition and fire intensity. Condition and intensity categories for some value attributes are necessary because fire effects or their importance often differ by ecosystem condition and/or fire intensity. For example, sequoia groves and ponderosa pine stands typically benefit from low-intensity fire when ecosystems are in a "maintenance mode" (no missed fire intervals) while stands and ecosystems might be harmed by high-intensity fire regardless of management mode. MARS was specifically designed to admit the negative and the beneficial effects of fire; in particular, it permits managers to capture the management concept that lowintensity fires may be used in certain cover types to maintain the system in a desirable state. Once the collection of value attributes is elicited and categorized by condition and intensity, the entire list is carefully reviewed by the group to ensure it is complete, appropriate for strategic planning, and that it does not include any double counting (identifying the same resource value under two 
headings). The final part of the elicitation process estimates the marginal values of each attribute under each intensity and ecosystem condition. These marginal values are known as marginal rates of substitution (ROS) in the economics literature. They indicate the rate at which one value can, in principle, be substituted for any of the others. A value of -1.0 defines the most important resource to protect (per hectare) from fire and a value of -0.5 defines a resource and condition that is half as important. Positive values, from 1.0 to 0.0 denote beneficial fire effects. They are interpreted similarly and are symmetrical with the negative values. These rates of substitution are the key valuation information produced from the MARS process and because they use a common currency, they are comparable across planning units.

\section{Results and discussion}

The results for value attribute categories and their rates of substitution are addressed starting with "human" resources such as developments and then natural designations such as wildlife. Values were elicited for the management mode "maintenance" at high and low fire intensities at all parks, and for the management mode "restoration" at high and low fire intensities for SEKI and GRCA.

The four parks have high value development that serves as a common currency at -1.0 for each combination of fire intensity (high and low) and management mode. These are of the highest importance to protect from fire. The value attribute "sensitive boundary" appears in GRCA, YELL and ROMO and under all modes and intensities it was very high for each of these parks. YELL had an elicited value of -1.0 for all four combinations of mode and intensity and GRCA had -0.80 for all four combinations. ROMO only has values for restoration mode at its boundary and the elicited values are -1.0 for high and low fire intensities. Protection of development and park boundaries, particularly boundaries near the Wildland-Urban Interface, are expected to have high importance to protect from fire; so the presence of the development and boundary attributes in three of the four parks and the elicited values associated with them at or near -1.0 are as expected.

Archaeological and cultural sites appeared in the attribute lists of three national parks: SEKI, GRCA and ROMO. Yellowstone did not have a separate attribute for cultural sites apart from "high value development". For the three parks with this attribute, all elicited values were negative, indicating that fire has the potential to damage such sites and therefore they are important to protect from fire. Under all combinations of management mode and fire intensity, the values ranged from -0.65 to -0.95 . SEKI had the lowest values $(-0.65)$ for low intensity fires under both management modes and -0.80 for high intensity fires (both management modes). GRCA had the same value, -0.85 , for all four combinations of intensity and management and ROMO had the highest value, -0.95 , for both high and low intensity fires under maintenance (no values for restoration mode). The differences among the parks are not unexpected for this 
attribute because of differences in expected fire behaviour at the archaeological and cultural sites for each park.

Each of the four parks has different wildlife, some of which have firesensitive habitats. Two parks identified wildlife habitat areas that are affected by fire management: ROMO identified elk winter habitat and GRCA identified goshawk and Mexican spotted owl habitats. Each park elicited values for individual species, but there are similarities among the values even though the species are very different. All values for low intensity fires, whether under maintenance or restoration, were positive. This indicates that both parks consider low intensity fire as beneficial for selected wildlife. Importance to improve values for low intensity fires ranged from 0.40 for Mexican spotted owl habitat to 0.55 for goshawk habitat. ROMO was in the middle-high range with 0.50 for elk habitat. For high intensity fires, such values were negative. The importance to protect values at high intensity have a wider range than the importance to improve values with ROMO showing an importance to protect value for elk habitat of -0.1 and GRCA showing -0.4 for Mexican spotted owl habitat and -0.5 for goshawk habitat. All except elk winter range at high intensity are mid-way between the extreme values of 0 and $+/-1.0$. An interpretation of the importance to protect habitat values would be that they are approximately half as important to protect as high value developments during high intensity fires.

Elicited values for short-return fire interval forests are similar in spite of being complex. SEKI and ROMO have ponderosa pine attributes and SEKI has a sequoia attribute. The only combination of intensity and mode that provides a comparison between parks is the low-intensity maintenance mode. For both parks, short-return fire interval forest types in maintenance mode have a high benefit from low-intensity fire events: sequoia groves have a value of 1.0 and ponderosa pine (both parks) has a value of 0.90 . It is difficult to compare the parks under the other combinations of intensity and mode because ROMO shows only one other value, the high-intensity maintenance mode combination (value of 0.50 ), and SEKI does not have this combination. Instead, SEKI has values under restoration reflecting negative effects at high-intensity $(-0.6$ for sequoia and -0.8 for pine) and benefits at low-intensity ( 0.8 for sequoia and 0.7 for pine). When viewed as a group, all short return interval values are positive except those under restoration for high-intensity fires. High intensity fires in stands under restoration would be harmful while other fires are beneficial.

Three national parks list attributes and values for long-return interval forest cover types. YELL and ROMO have lodgepole pine and spruce-fir, and SEKI and ROMO have a mixed-conifer type. Only the SEKI mixed-conifer is in restoration mode, with values of -0.3 for high-intensity and 0.6 for low-intensity. All other long-return interval cover types for these parks were considered to be in maintenance mode. Among the parks with long-return interval cover types, very similar values were elicited for importance to improve with fire when the stands are in maintenance mode. All of the elicited values for both high and low fire intensity are 0.8 , except for lodgepole pine in ROMO at low fire intensity (0.70). 
Table 1: $\quad$ Fire management meta-value attributes for four national parks.

\begin{tabular}{|c|c|}
\hline $\begin{array}{c}\text { Short Fire Return Interval Cover } \\
\text { Types }\end{array}$ & $\begin{array}{c}\text { Cultural and Archaeological } \\
\text { Sites }\end{array}$ \\
\hline Sequoia (SEKI) & Cultural Trees (SEKI) \\
\hline Ponderosa Pine (SEKI, ROMO) & Cultural Sites (ROMO) \\
\hline Long Fire Return Interval Cover \\
Types & Sensitive Archaeological (GRCA) \\
\hline Spruce-Fir (YELL, ROMO) & High Value Development \\
\hline Lodgepole Pine (YELL, ROMO) & (All Parks) \\
\hline Mixed Conifer (SEKI, ROMO) & Wildlife Habitat \\
\hline & Goshawk Nesting (GRCA) \\
\hline Sensitive Boundary & Mexican Spotted Owl (GRCA) \\
\hline (GRCA, YELL, ROMO) & Elk Winter Range (ROMO) \\
\hline
\end{tabular}

Examination of the attribute lists and elicited values from the four national parks suggests that construction of a set of meta-value attributes would be promising. Definition of a meta-value attribute appears straightforward when multiple parks have identified the same value attribute, such as "high value development". Unique values, such as the value of protecting volcanic monitoring sites in YELL, are not useful for the meta-value list because they do meaningfully compare or contrast with attributes in other parks. Other unique attributes may be compared across parks as they fit broader categories. An example is combining goshawk nesting sites and Mexican spotted owl habitat in GRCA with winter elk habitat in ROMO to define a "wildlife habitat" metavalue attribute. If such meta-value attributes are viable, they have the potential to suggest resource values for other planning units and reference points in marginal valuation for other parks. Analysis of the four park data sets provides a list of park meta-value attributes. Table 1 lists the meta-value attributes (bold) and their specific value attributes as defined by the parks.

The unique features of U.S. national parks suggest a range of values for each meta-value attribute. Figure 1 shows the ranges and midpoints graphically to enhance the comparisons of relative values and their ranges. Immediately apparent is the range of values for wildlife habitat under restoration and high intensity fire. This is the highest range in the figure at 0.4 values units, or $20 \%$ of the overall range. This is not surprising as high intensity fires often have a wider range of impacts. Five of the 16 categories have the narrowest range of 0.0 units. These are high value development, ponderosa/sequoia for either management mode at low fire intensity, long return interval conifers in maintenance mode at low fire intensity and wildlife habitat in maintenance mode at high fire intensity.

Resources designated, created and maintained by humans such as developments, boundaries and cultural and archaeological sites, tend to have high importance to protect from fire. The range of these values is between -0.65 and -1.0. Resources created and maintained by nature tend to have importance to 
improve, particularly at low fire intensities or when in maintenance mode for management. Only when nature's resources are in a restoration mode or when high fire intensity may damage a resource do they incur an importance to protect from fire. Unlike the human created resources, nature's meta-value attributes did not follow a consistent result of "always protect" or "always improve".

Although for a given attribute and management mode/fire intensity combination, either "always protect" or "always improve" may be applied. Importantly, none of the meta-value attributes under any mode/intensity combination have a range that crosses zero. This suggests that meta-value attributes may be useful descriptors of a shared set of environmental values across at least the four national parks evaluated.

\section{Conclusions}

The results provide a means of addressing the two fundamental questions posed for this paper: can potentially useful meta-value attributes be constructed for

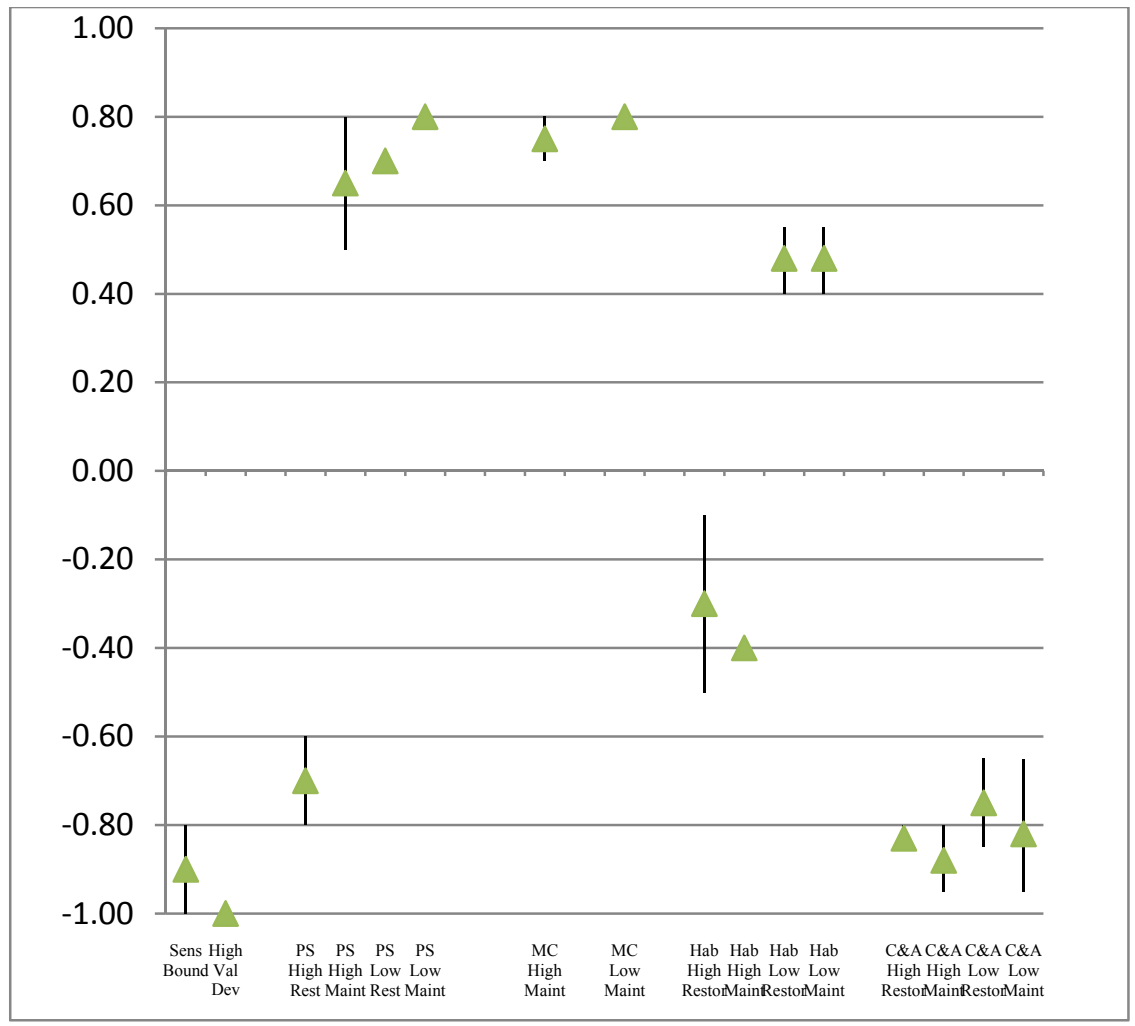

Figure 1: Ranges and mid-points for meta-value attributes. PS denotes ponderosa and sequoia, MC denotes mixed conifer, Hab denotes wildlife habitat and C\&A denotes cultural and archaeological sites. 
U.S. national parks and how would those values compare. Interpretation of the results suggests that meta-value attributes are a viable construct to enable broader interpretation of marginal rates of substitution. For cover types, this is greatly facilitated by distinguishing between long and short fire return interval systems. While we express caution considering that only four parks were sampled, our descriptive data suggest that for most meta-value attributes there is evidence of consistency in valuation across these western U.S. national parks. Given that MARS was independently applied using four different "expert" groups, the consistency suggests that the results of MARS may be largely independent of the particular expert group. The consistency of values is shown by the tight ranges produced across the parks and by the fact that none of the ranges extended across zero. To the extent that the meta-values are viable and consistent, they can be used on other parks to facilitate the valuation process. Parks initiating the marginal valuation process can use the meta-value attributes to better identify their own specific planning unit level attributes. Public officials charged with management of treasured natural resources in the western U.S. parks exhibited a high level of consistency across fire intensities and ecosystem conditions.

\section{References}

[1] Holmes, T. P., Prestemon, J. P. \& Abt, K. L., An Introduction to the Economics of Forest Disturbance (Chapter 1). The Economics of Forest Disturbances: Wildfires, Storms, and Invasive Species, ed. T. P. Holmes, J. P. Prestemon \& K. L. Abt, Springer Science + Business Media B. V., pp. 3-14, 2008.

[2] U. S. Senate, Department of the Interior, Environment, and Related Agencies Appropriations Bill, 2008.

[3] Rideout, D. B., Ziesler, P. S., Kling, R., Loomis, J. B. \& Botti, S. J., Estimating rates of substitution for protecting values at risk for initial attack planning and budgeting. Forest Policy and Economics, 10, pp. 205-219, 2008.

[4] Samuelson, P. A., The Pure Theory of Public Expenditure. Review of Economics and Statistics, 36, pp. 387-389, 1954.

[5] Samuelson, P. A., Diagrammatic Exposition of a Theory of Public Expenditure. Review of Economics and Statistics, 37, pp. 350-356, 1955.

[6] Loomis, J. B., Integrated public lands management: principles and applications to national forests, parks, wildlife refuges, and BLM lands, Second Edition, Columbia University Press: New York, NY, 2002.

[7] Champ, P. A., Boyle, K. J. \& Brown, T. C., (eds). A Primer on Nonmarket Valuation, Kluwer Academic Publishers: Dordrecht, The Netherlands, 2003.

[8] Davis, D. D. \& Holt, C. A., Experimental Economics, Princeton University Press: Princeton, N.J.: 1993. 